University of Nebraska - Lincoln

DigitalCommons@University of Nebraska - Lincoln

Si-Hwang Liou Publications

Research Papers in Physics and Astronomy

August 1987

\title{
Superconducting Y-Ba-Cu-O oxide films by sputtering
}

M. Hong

AT\&T Bell Laboratories, Murray Hill, New Jersey

Sy_Hwang Liou

University of Nebraska-Lincoln, sliou@unl.edu

J. Kwo

AT\&T Bell Laboratories, Murray Hill, New Jersey

B.A. Davidson

AT\&T Bell Laboratories, Murray Hill, New Jersey

Follow this and additional works at: https://digitalcommons.unl.edu/physicsliou

Part of the Physics Commons

Hong, M.; Liou, Sy_Hwang; Kwo, J.; and Davidson, B.A., "Superconducting Y-Ba-Cu-O oxide films by sputtering" (1987). Si-Hwang Liou Publications. 17.

https://digitalcommons.unl.edu/physicsliou/17

This Article is brought to you for free and open access by the Research Papers in Physics and Astronomy at DigitalCommons@University of Nebraska - Lincoln. It has been accepted for inclusion in Si-Hwang Liou Publications by an authorized administrator of DigitalCommons@University of Nebraska - Lincoln. 


\title{
Superconducting Y-Ba-Cu-O oxide films by sputtering
}

\author{
M. Hong, S. H. Liou, J. Kwo, and B. A. Davidson \\ AT\&T Bell Laboratories, Muray Hill, New Jersey 07974
}

(Received 5 June 1987; accepted for publication 13 July 1987)

\begin{abstract}
We have prepared superconducting thin films of $\mathrm{Y}-\mathrm{Ba}-\mathrm{Cu}-\mathrm{O}$ with $T_{\mathrm{c}}$ onsets above $95 \mathrm{~K}$ by both diode and magnetron sputtering. Films with full superconductivity $(R=0$ ) at $85 \mathrm{~K}$ have been produced by do magnetron sputtering. The compositions of the films are fairly uniform across an area $50 \mathrm{~mm}$ in diameter and through the film thickness. Structural properties of the films were studied by $x$-ray diffraction. Critical current densities in the range of 3000 to $10^{4} \mathrm{~A} /$ $\mathrm{cm}^{2}$ have been measured at $4.2 \mathrm{~K}$.
\end{abstract}

The recent discovery of the new class of high critical temperature superconducting oxides, particularly the Y-Ba-Cu-O system ${ }^{2}$ with $T_{c}$ 's in excess of $90 \mathrm{~K}$, has caused extraordinary interest and intensive activity in scientific and technological research. The possibiitty of operating superconducting devices and magnets at or above liquid-nirrogen temperature is regarded as an unprecedented technological development. There are potential applications in microelectronics and computers, sensors, energy storage, power transmission, magnets for high-energy physics accelerators, fusion reactors, and nuclear magnetic resonance (NMR) imaging systems. Besides the practical applications, the discovery of these very high $T_{r}$ metallic oxides has raised many fundamental questions about the nature of the superconductivity in this class of materials. These questions include the origins of the high $T_{c}$ 's, whether a new mechanisno of superconductivity is present, or whether the Bardeen-CooperSchrieffer (BCS) theory, inciuding its extensions to strong coupling, can describe the superconuchetivity in these materials.

Currently most of the research activity has focused on bulk samples obtained from powder processes. ${ }^{2-5}$ or equal interest for practical applications, as well as providing more quantitative mesurements on basic superconducting parameters, is the preparation and study of high $T_{c}$ oxide fikms. In this ietter we report our work in fabricating Y-Ba-Cu-O films by both diode and magnetron sputtering techniques from composite oxide targets. Superconducting films (50 $\mathrm{mm} \times 50 \mathrm{~mm}$ ) with $T_{c}$ onsets of $95 \mathrm{~K}$ have been successfully and reproducibly obtained.

The diode and magnetron sputtering systems used here, although not elaborately designed or constructed, are not commercially avaliable. The detailed description of the systerns and the operating parameters have been pubished earlier. ${ }^{6.7}$ Films $0.4-2.0 \mu \mathrm{m}$ thick were deposited on substrates of sapphire and $\mathrm{Al}_{2} \mathrm{O}_{3}$ with deposition rates of $0.05-0.3 \mathrm{~mm}$ s. The argon pressure during deposition was 5 m Torr for magnetron sputtering and $30 \mathrm{~m}$ Tor for diode sputtering. The substrate holder temperatures could be varied from room temperature to $500^{\circ} \mathrm{C}$. The results reported here are from the films deposited at room temperature. Compacted and sintered $\mathrm{Y}-\mathrm{Ba}-\mathrm{C} n-\mathrm{O}$ oxide powders with various con:positions were used as sputtering targets. The fim composithon was examined by Rutherford backscattering spectrometry (RBS). The structure of the flins was studied using $\mathrm{x}$-ray difraction analysis.
The as-deposited films are amorphous from both $\mathrm{x}$-ray and electron diffraction, and are generally insulating. Postdeposition oxygen annealing treatments at temperature above $800^{\circ} \mathrm{C}$ are necessary to transform the films to become superconducting at low temperatures. Inadequate heat treatments such as annealing at ternperatures below $750^{\circ} \mathrm{C}$ usually give flms a semiconducting behavior before the superconducting transitions. The critical transition temperatures were measured using both ac and de resistance versus temperature data. The ac method employed four-point pressure contacts usually with a small applied current of 0.05 to $0.25 \mu \mathrm{A}$. The de metrod also uses the four-point technique but switching the polarization of the applied current during the measurements. The applied current in the do method is larger, typically around 10-100 $\mu \mathrm{A}$. Therefore, the $T_{c}$ 's obtained in the dc method, particularly at the complete superconducting state ( $R=0$ ), are slightly lower than the values by the ac method.

Figures $1(a)$ and $1(c)$ are the $x$-ray diffractometer traces of the post-deposition oxygen annealed $\mathrm{Y} \cdot \mathrm{Ba} \cdot \mathrm{Cu} \cdot \mathrm{O}$ fulms $0.7 \mu \mathrm{m}$ thick deposited on sapphire and $\mathrm{Al}_{2} \mathrm{O}_{3}$ substrates, respectively. The majority phase of the fims is similar to the orthorhombic structure observed for high $T_{c} \sin$ -

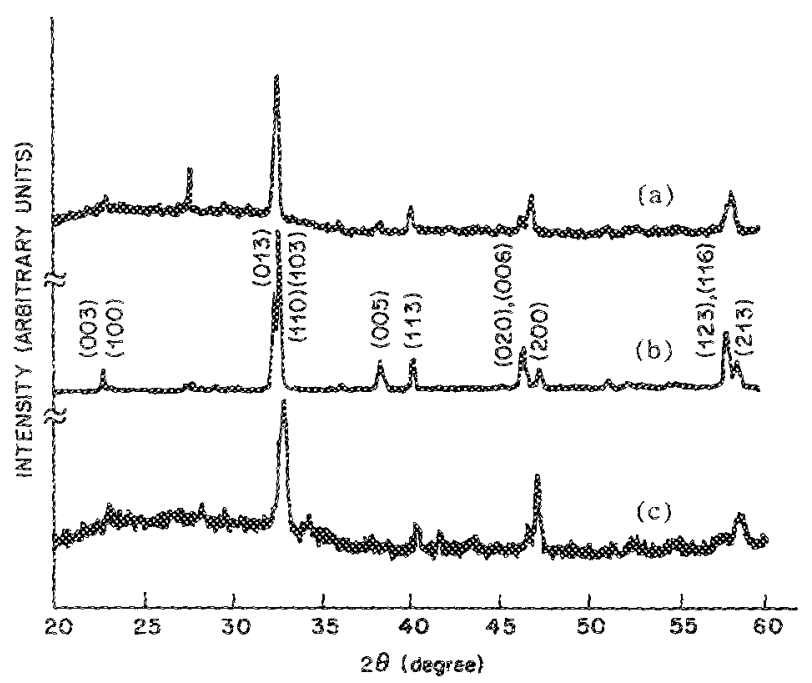

FIG 1. X-tay difraction traces of post axygen-annuled $Y-B a-C u-O$ flms on a sapphire substrate and (c) an randomly oriented $A_{2} \mathrm{O}_{3}$ substrate. The $x$-ray diffractian data in (b) was taken on a sintered powder sample with a composition of $\mathrm{Y}_{2} \mathrm{~Pa}_{2} \mathrm{Cu}_{3} \mathrm{O}_{7} \ldots$ 


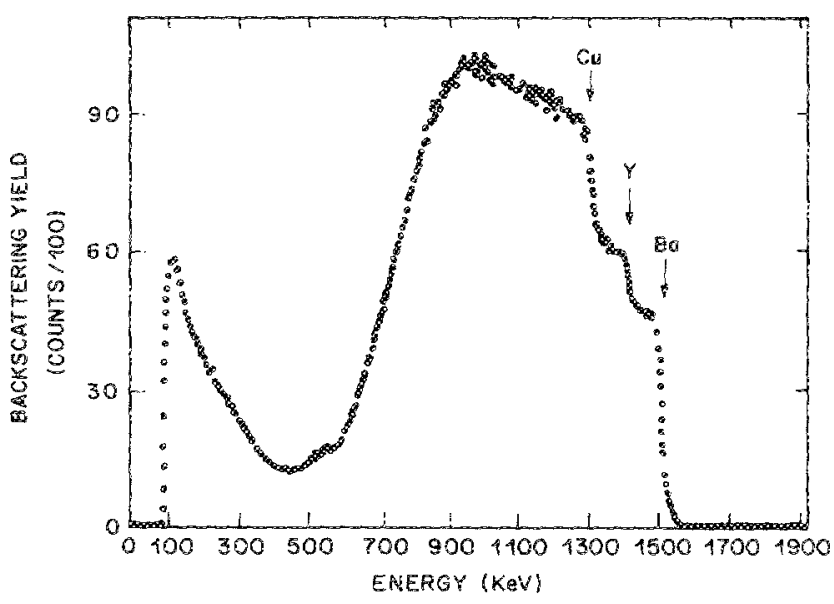

FIG. 2. Rutherford backscattering yield for a dc magnetron sputtered $\mathrm{Y}-\mathrm{Ba}-\mathrm{Cu}-\mathrm{O}$ film.

gle-phase bulk-powder $\mathrm{Y}_{1} \mathrm{Ba}_{2} \mathrm{Cu}_{3} \mathrm{O}_{7-x}$ samples [Fig. 1(b) 1. This "high $T_{c}$ " phase, in fact, has always been obtained in films with a somewhat wider range of compositions around the stoichionetry of $Y_{1} \mathrm{Ba}_{2} \mathrm{Cu}_{3} \mathrm{O}_{y}$. So far the highest $T_{c}$ 's in our sputtered films have been found in the $\mathrm{Cu}$-rich films with compositions approximately of $\mathrm{Y}_{1} \mathrm{Ba}_{1.9} \mathrm{Cu}_{4.2} \mathrm{O}_{y}$.

A closer examination of the $\mathrm{X}$-ray diffraction data show/s that there is a preferred orientation in the heat-treated films with the $c$ axis lying in and the $a$ axis perpendicular to the film plane. This is evidenced by comparing the intensities of the (006), (020), and (200) peaks in the films with those from the randomly oriented powders. Moreover, the (200) difraction peak of the films shifts siightiy toward the lower angle indicating a larger lattice spacing along the $a$ axis. Thus, the diference in lattice spacing between the $a$ and $b$ axis is smaller in the films. The result may indicate a more random ordering of oxygen in the films than in the nowder, and may well explain why the $T_{c}$ 's of the sputtered $Y-B a-C u-O$ flms are in general lower than those obtained in the bulk powder.

We found that in our sputtered flins the superconducting properties do not seem to be directiy correlated to the crystallographic structure (or phase). The "right" phase in the sputtered films is only a necessary condition, i.e., may not lead to the full superconductivity because of the lack of the percolating path connecting the supercondncting islands. Evidently a significant portion of the heat-treated fims is still amorphous as can be seen from the $x$-ray diffracton data. Prolonged heat treatments at high temperature $\left(>850^{\circ} \mathrm{C}\right)$ in the oxygen atmosphere which have been designed to eliminate the amorphous region as well as to increase the ordering of the orygen in the right phase were found to increase the intensity of the minority phases. These additional $x$-ray diffraction peaks in the range between $(2 \theta=) 28^{\circ}$ and $32^{\circ}$ using copper $K_{\alpha}$ radiation could be some second phases in the films or may be caused by the film/ substrate interaction, and need further identification. The microscopic distribution of the crystailine and amorphous phases in the film now being studied by the transmission electron microscopy in our laboratory is important and may
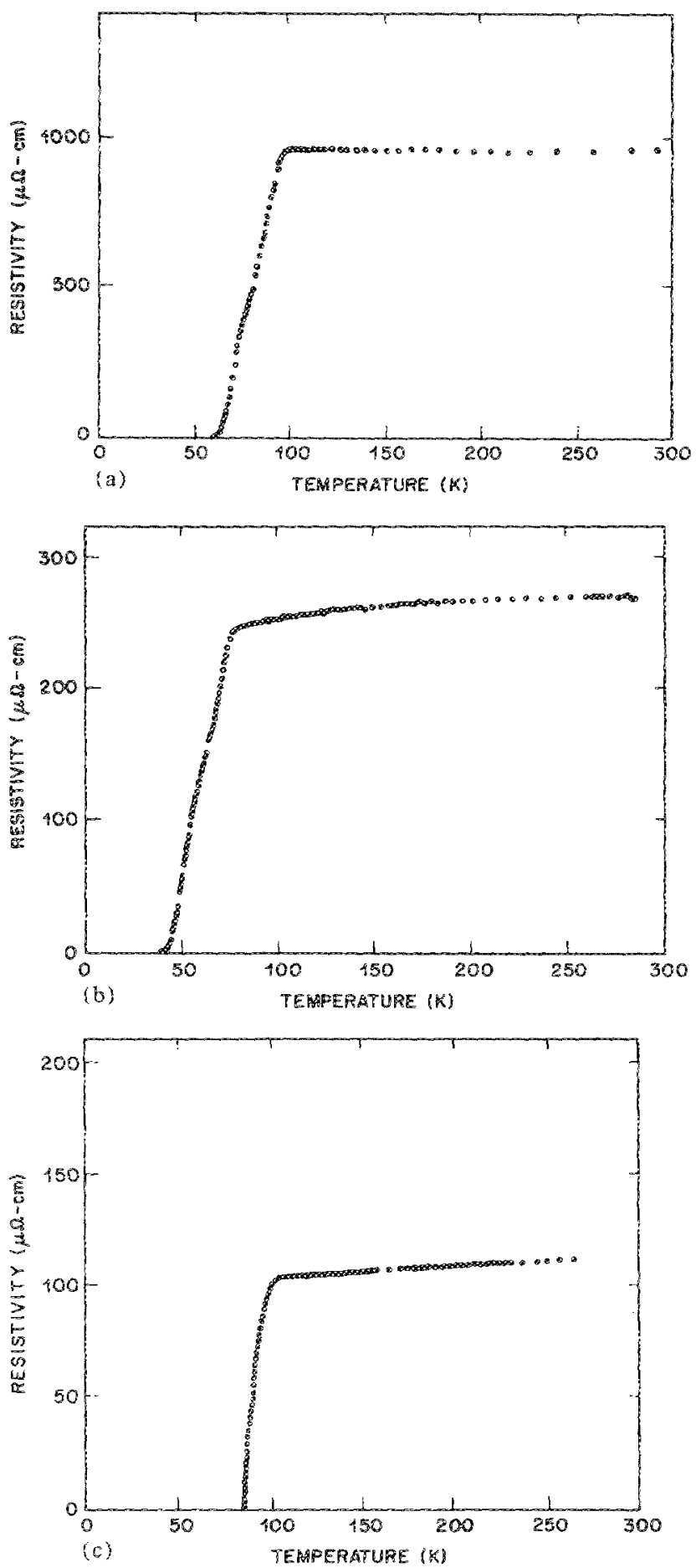

FiG. 3. Resistivity vs temperature for diode and magnetron sputtered Y-Bb-Cu-O fims: (a) typical fims from dode or masnetron spatiering for annealing at $850-900^{\circ} \mathrm{C}$ in oxygen for more than $0.5 \mathrm{~h} \mathrm{(b)}$ films annealed at $900^{\circ} \mathrm{C}$ for a few minutes or annealed below $825^{\circ} \mathrm{C}$, and (c) the highest transition obtained from a magnetron-sputtered ilm neat treated at $850^{\circ} \mathrm{C}$ for $\sim 1 \mathrm{~h}$ in oxygen.

lead to a better understanding of the superconducting properties.

A typical RBS curve of a post-oxygen heat-treated $X-B a-C u-O f m$ is shown in Fig. 2 from which the chemical composition of the film was determined to be $Y_{i} \mathrm{Ba}_{1.9} \mathrm{Cu}_{4.2} \mathrm{O}_{y}$ (at. \%). From the RBS examinations on the entire films we found that the composition variation is no 
more than $10 \%$ across the sputtered film area, $50 \mathrm{~mm}$ in diameter for magnetron sputtering. For diode sputtered films, the composition is much more uniform across the film area which is $25 \mathrm{~mm}$ in diameter. The size of the uniformity is mainly determined by the size of the targets. The composition is also uniform through the film thickness.

We were able to obtain very consistent superconducting and structural properties in the sputtered fims from run to run as long as we used the same target. This is consistent with the observation that the film composition does not vary much from one film to another when the sputtering conditions are kept the same.

In order to determine the oxygen (or other gas impurity such as argon) content, fims with thinner thickness less than $0.1 \mu \mathrm{m}$ are needed. However, in such a thin-fin regime the film/substrate interaction can be significant, and the use of the substrates then becomes critical.

In general, the resistivity versus temperature behaviors of the superconducting films are classified into two categories and are shown in Figs. 3(a) and 3(b). Freshly deposited films with heat treatments at $850-900^{\circ} \mathrm{C}$ in oxygen for over 30 min show a $T_{r}$ onset of $95 \mathrm{~K}$ with $R=0$ at about $60-70 \mathrm{~K}$. The film in Fig. $3(\mathrm{a})$ has $R=0$ at $60 \mathrm{~K}$ and a midpoint around $75 \mathrm{~K}$. These films usually do rot age over a period of a few days in the dry air. However, for films with improper heat treatments, such as annealing below $825^{\circ} \mathrm{C}$ or a few minutes at $900^{\circ} \mathrm{C}$, the $T_{c}(R=0)$ is reduced substantially, to $36-40 \mathrm{~K}$ in a few days even for samples kept in the dry air. The $T_{c}$ 's of all the films are reduced drastically when placed in the surrounding of water or water moisture. The aging phenomenon in the films as well as in the sintered powders certainly causes concern in the practical appications. Although most of the films fall into the above categories, the sharpest transition so far obtained in a de magnetron-sputtered film annealed at $850^{\circ} \mathrm{C}$ for $\sim 1$ h and then slowly cooled under cxygen is shown in Fig. 3 (c), with a $T_{c}$ onset above $95 \mathrm{~K}$, beconing fully superconducting at $85 \mathrm{~K}$.

For the film with $T_{c}$ at $85 \mathrm{~K}(R=0)$, the critical current at $4.2 \mathrm{~K}$ is $66 \mathrm{~mA}$ using $1, \mu \mathrm{V}$ in voltage rise as a criterion. The thickness of the film is $0.7 \mu \mathrm{m}$. If the whole cross section of the fim were assumed to be uniformly superconducting this impiies a critical current density over $3000 \mathrm{~A} /$ $\mathrm{cm}^{2}$. This is very much a lower bound estimate in view of the inhomogeneity of the two-dimensional fim, the portion of the amorphous region, and the interaction between the film and the substrate. More recently, a much higher $J_{c}$ of $10^{4} \mathrm{~A}$ $\mathrm{cm}^{2}$ at $4.2 \mathrm{~K}$ has also been obtained in our sputtered films deposited on a different substrate of $\mathrm{MgO}$ single crysta! with $T_{c}(R=0)$ around $55 \mathrm{~K}$.
The room-temperature resistivity of the fims should be low enough to ensure the cccurrence of the superconductivity. The values are generally around $100-1000 \mu \Omega \mathrm{cm}$. Tf the values are too high over $5000 \mu \Omega \mathrm{cm}$ nilms are often semiconducting or even insulating. However, we also found that lowering the resistivity alone would not increase the superconducting transition temperatures. In other words, there seerns to be no correlation between the $T_{c}$ 's and the room-temperathre resistivities once the latter are low enough.

In conclusion, we have clearly demonstrated that the high $T_{c}$ oxide superconducting films with $T_{c}$ onset of $95 \mathrm{~K}$ can be grown by simple and common techniques such as sputtering. We have studied the crystallographic phases, the film texture, the composition, and the wniformity in the high $T_{c}$ finms. Reasonably critical currents have been obtained. Future work will be focused on the study of the film microstructure, the increase of the critical currents, and the film/ substrate interaction. We will also carry out basic superconductivity measurements and fabricate devices for practica! applications.

During the course of this research work, we learned that Laibowitz et al. at IBM Yorktown Heights ${ }^{8}$ and Hammond et al. at Stanford University" have used electron beam evaporation to obtain $Y-B a-C u-O$ films with $T_{c}(R=0)$ above 80 $\mathrm{K}$. Somekh et al. ${ }^{10}$ of the University of Cambridge have also used dc magnetron sputtering to prepare superconducting $\mathrm{Y}-\mathrm{Ba}-\mathrm{Cu}-\mathrm{O}$ films.

'M. K. Wu, J. R. Ashburn, C. J. Torng, R. H. Hor, R. L. Meng, L. Gao, Z. J. Huang, Y. Q. Wang, and C. W. Chu, Phys. Rev. Lett. \$8, 908 (1987). 2R. Y. Cava, E. Batlogg, R. B. van Dover, D. W. Murphy, S. Sunstine, T. Siegrist, J. P. Renteika, E. A. Rietman, S. Zahurak, and G. Espinosa, Phys. Rev. Lett. 58, 1676 (1987).

3P. M. Grant, R. B. Beyers, D. M. Engler, G. Eim, S. S. P. Parkin, M. L. Ramirez, V. Y. Lee, A. Nazzal, J. E. Vazquez, and R. J. Savoy, Phys. Rev. B 35, $7242(1987)$.

${ }^{4}$ J. Moreland, J. W. Ekin, I. F. Goodrich, T. E. Capobianco, A. E. Clark, J. Kwo, M. Hong, and S. M. Liou, Phys. Rew. B 35, 8856 (1987).

${ }^{5}$ M. D. Kirk, D. P. E. Smith, D. B. Mitz, J.Z. Sun, D. J. Webb, K. Char, M. R. Hahn, M. Naito, B. Oh, M. R. Beasley, T. I. Geballe, R. H. Hammond, A. Kapituinik, and C. F. Quate, Phys. Rev. B 35, 8350 (1987).

M. Hong, E. M. Gyorgy, and D. D. Bacon, Appl. Phys, Letr. 406 (1984).

${ }^{7}$ S. H. Liou and C. L. Chien, J. Appi. Phys. 55, 1820 (1984).

"R. B. Laibowitz, R. I. Koch, P. Chaudhari, and R. J. Gambino, Mhys. Rev. B 35, 8821 (1987).

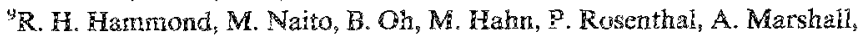
N. Missert, M. R. Beasley, A. Kapiruhik, and T. H. Geballe, Materials Research Society Conference Proceedings, Vol. EA-11, on High Tcmperakure Superconductors (Materials Research Society, Pitsbburgh, PA, 1987).

toR. E. Somekh, M. G. Blamire, Z. H. Barber, K. Butler, J. H. James, G. W. Morris, E. J. Tomlinson, A. P. Schwarzenberger, W. M. Stobbs, and J. E. Evctes, Nature 326, 857 (1987). 